\title{
A alternância entre o futuro do pretérito e o pretérito imperfeito no português brasileiro: Variação estável ou mudança em progresso?
}

\author{
Aline da Silva Santos (UEFS)* \\ https://orcid.org/0000-0002-6472-4265
}

Norma Lucia Fernandes de Almeida (UEFS)**

https://orcid.org/0000-0002-3369-4251

\section{Resumo:}

O futuro do pretérito (FP) é o tempo verbal do modo indicativo empregado para se fazer referência a um acontecimento posterior a um passado, ou um acontecimento que poderá ou não ocorrer, dependendo de uma condição, além de transmitir valores modais de hipótese, possibilidade, desejo, necessidade etc. O FP costuma variar, em alguns contextos de uso, com o pretérito imperfeito (PI), que, tradicionalmente, é usado para se falar de hábito ou acontecimento que ocorria com frequência no passado ou ainda para se referir a um fato interrompido por outro fato concomitante. Assim, expressões como, por exemplo, "se eu fosse você, comprava mais livros" ou "se eu fosse você, compraria mais livros" e ainda as formas perifrásticas "ia comprar" e "iria comprar", respectivamente, costumam ser usadas com o mesmo valor de verdade. Pesquisas sobre esse tema, amparadas na Teoria da Variação e da Mudança Linguística, já foram desenvolvidas em diferentes regiões do Brasil e a finalidade deste artigo é, portanto, descrever e correlacionar resultados de algumas dessas pesquisas, observando, sobretudo, se esses resultados apontam para um fenômeno de variação estável ou de mudança em progresso.

Palavras-chave: Variação e mudança. Português brasileiro. Futuro do pretérito. Pretérito imperfeito.

\section{Abstract:}

\section{The alternation between the conditional future tense and imperfect past tense in brazilian portuguese: Stable variation or change in progress?}

\footnotetext{
* Doutoranda em Estudos Linguísticos - Universidade Estadual de Feira de Santana (UEFS). Lattes: http:// lattes.cnpq.br/3988526074633147.E-mail: linedss@gmail.com

** Doutora em Linguística. Professora titular da Universidade Estadual de Feira de Santana (UEFS). Lattes: http://lattes.cnpq.br/0369000710579780.E-mail: norma.uefs@gmail.com
} 
The conditional future tense (FP) is the verb tense in the indicative way used to refer to an event after a past, an event that may or may not occur, depending on a condition, in addition to transmitting modal values of hypothesis, possibility, desire, need, etc. The FP tends to vary, in some contexts of use, with the imperfect past tense (PI), which is traditionally used to talk about a habit or event that occurred frequently in the past or to refer to a fact interrupted by another fact concomitant. Thus, expressions such as "if I were you, buy more books" or "if I were you, buy more books" and the periphrastic forms "would still" comparable and "would buy", respectively, are usually used with the same truth value. Research on this topic, supported by the Theory of Linguistic Change, has already been developed in different regions of Brazil and the purpose of this article is, therefore, to describe and correlate results of some of these researches, observing, above all, if these results point to a phenomenon of steady variation or change in progress.

Keywords: Variation and change. Brazilian portuguese. Conditional future tense. Imperfect past tense

\section{Introdução}

A proposta deste artigo é analisar algumas pesquisas sociolinguísticas que foram desenvolvidas no Brasil sobre a variação na expressão do tempo futuro do pretérito (FP), que alterna seu uso com o pretérito imperfeito (PI), ambos do modo indicativo. Nosso intuito é discutir se os resultados dessas pesquisas apontam para um fenômeno de variação estável ou de mudança em progresso.

A alternância entre FP e PI costuma acontecer tanto em verbos não modais, formados por estruturas sintéticas (ex.: Se fosse possível, 'viajaria' mais/ Se fosse possível, 'viajava' mais) e perifrásticas (ex.: 'iria viajar' e 'ia viajar'), mas também no uso de verbos modais, formados por verbos auxiliares e principais, como 'poder', 'dever', 'precisar', 'querer', 'ter de/ter que' + infinitivo (ex.: 'deveria viajar/devia viajar').

Embora o FP seja apresentado tradicionalmente no conjunto dos verbos do indicativo - modo que exprime a atitude de certeza do falante em relação ao fato expresso pelo verbo -, é um tempo verbal que possui pecu- liaridades que o distinguem dos demais tempos do indicativo, pois expressa o irrealis, que, segundo Givón (2001), se refere a uma situação na qual há ausência de realidade, ou seja, os enunciados demonstram que a ocorrência de um fato não é certa, como neste exemplo: "Se me fosse dado um dia, outra oportunidade, eu nem olhava o relógio/ 'Seguiria' sempre em frente [...]" (Mário Quintana, grifo nosso). Além disso, o FP pode indicar diferentes circunstâncias modais, tais como condição, hipótese, intenção, possiblidade, probabilidade, desejo e necessidade.

Já no que diz respeito ao PI, é um tempo passado inconcluso, utilizado para se referir a um fato interrompido por outro fato concomitante e para falar de hábito ou acontecimento que ocorria com frequência no passado, ex.: "Eu sozinho menino entre mangueiras / lia a história de Robinson Crusoé" (Carlos Drummond de Andrade, Infância. Grifo nosso). Mas o PI também é empregado, como vimos, em lugar do FP.

Para tratarmos, portanto, desse tema, nosso artigo se estrutura da seguinte for- 
ma: abordaremos a mudança linguística, do latim para o português, dos dois tempos em análise; faremos uma explanação acerca da Teoria da Variação e da Mudança Linguística; falaremos a respeito da realidade sociolinguística do português brasileiro; apresentaremos os estudos que constituem nossa análise bibliográfica e, por fim, traçaremos algumas conclusões.

\section{0 futuro do pretérito e o pretérito imperfeito: as mudanças em tempos verbais do latim para 0 português}

Os tempos verbais em latim eram distribuídos em dois sistemas: o infectum e o perfectum. 0 infectum era o tempo de ação incompleta e expressava fatos no presente, no passado e no futuro. 0 infectum era formado pelos seguintes tempos e modos verbais: presente do indicativo, pretérito imperfeito do indicativo, futuro do presente, presente do subjuntivo, pretérito imperfeito do subjuntivo e o imperativo. No que diz respeito ao perfectum, era o tempo da ação completa, que por sua vez reunia o pretérito perfeito do indicativo, pretérito mais-que-perfeito do indicativo, futuro perfeito do indicativo, pretérito perfeito do subjuntivo e pretérito mais-que-perfeito do subjuntivo.

O pretérito imperfeito, portanto, é um dos tempos que foi conservado na passagem dos verbos latinos para as línguas românicas. Mattos (2001) pesquisa sobre a evolução dos tempos verbais e apresenta os seguintes exemplos do imperfeito na passagem do latim para o português: "amabam > amava; debeam (por debebam) > devia; vedeam (por vendebam) > vendia; puniam (por punibam) > punia" (p. 23).

Quanto ao futuro do pretérito, é uma criação das línguas românicas. Segundo
Mercer (2011, p.386), como o latim não possuía uma forma própria para o futuro do pretérito, então assumia essa função o maisque-perfeito do subjuntivo, "que em latim vulgar passou a ter a concorrência de uma construção perifrástica paralela à do futuro, constituída de infinitivo do verbo principal mais habebam".

Ainda sobre a formação do futuro na passagem do latim vulgar para as línguas românicas, Câmara Jr. (1975, p. 132) afirma que, através da combinação do infinitivo imperfeito com o presente do verbo habēre (haver), constituiu-se, em boa parte das línguas românicas, uma locução volitiva, que focalizava, do presente, a vontade de que um fato acontecesse, como, por exemplo, cantare habeo. E, ao mesmo tempo, estabeleceu-se uma locução paralela, com referência no passado, formada de infinitivo com o pretérito imperfeito de habēre (cantare habebam). É dessa forma, portanto, que surgem, respectivamente, o futuro do presente e o futuro do pretérito.

No que diz respeito à forma, Câmara Jr. (1975, p. 132) esclarece que houve uma "aglutinação dos dois vocábulos, com uma redução fonética violenta das formas de habere", mudança que começou através do "esvaimento da consoante /b/ intervocálica; as vogais, assim postas em contato, se assimilaram, ditongaram e contraíram". Logo, com o futuro do pretérito, aconteceu o seguinte processo: "a(b) e (b)a > ea > ia, etc.". Câmara (2002, p. 85) evidencia essa mudança do futuro do pretérito desta maneira: "AMARE + HABEBAM > amar + *h (ab/ea) > AMARIA".

Câmara Jr. (1975) destaca ainda que o futuro do pretérito tem um uso muito restrito, devido ao fato de depender de circunstâncias específicas. E também acrescenta: “É preciso que o sujeito falante, reportandose ao passado e continuando a situar-se no 
presente, considere, dessa posição por assim dizer ubíqua, o que ocorreu posteriormente no momento do passado a que assim se reportou" (p.133). Em seguida, o autor afirma que continuam presentes na língua coloquial "as condições que faziam no latim as formas futuras serem de emprego parcial, confinadas à língua escrita e a certas situações orais formalísticas" (p. 133-134).

\section{A Teoria da Variação e da Mudança Linguística}

A teoria da variação e mudança linguística foi sistematizada na década de 60 , a partir dos estudos de Wiliam Labov na ilha de Martha's Vineyard, no Estado de Massachusetts (EUA), sobre a centralização dos ditongos /ay/ e /aw/, como também a respeito da estratificação do /r/ em lojas de departamentos na cidade de Nova York. Além desses estudos, outro marco da sociolinguística é a organização dos princípios empíricos da teoria, elaborados por Labov, Weinreich e Herzog, que resultou na publicação do livro "Fundamentos empíricos para uma teoria da mudança linguística”, em 1968.

Desse modo, a sociolinguística variacionista ocupa-se da análise da variação e da mudança linguística em comunidades de fala, partindo do pressuposto de que a língua e a sociedade mantêm uma inter-relação, a qual é responsável pela característica heterogênea da língua. Essa percepção caracteriza a sociolinguística como um campo da Linguística que rompe com a noção de língua homogênea, opondo-se, sobretudo, ao estruturalismo, modelo teórico que no momento preponderava nos estudos linguísticos e era liderado por Ferdinand de Saussure.

Saussure defendia a unicidade e a homogeneidade como propriedades inerentes à língua. Na visão do estruturalista, a língua "não constitui [...] uma função do falante: é o produto que o indivíduo registra passivamente" (SAUSSURE, 2012 [1916]), por isso faz uma oposição entre língua (fr. langue) e fala (fr. parole), elegendo a primeira como objeto de estudo da linguística e desprezando a fala, a qual seria uma atividade individual. Consoante Saussure (2012 [1916], p. 45), a separação entre língua e fala implica distinguir "ao mesmo tempo: 1으 - o que é social do que é individual; $2^{\circ}$ - o que é essencial do que é acessório e mais ou menos acidental".

Para Labov (2008 [1972], p. 217), não obstante Saussure compreendesse a linguística como parte de uma ciência que analisa os signos no seio da vida social, essa concepção era paradoxal, porque as pesquisas estruturalistas analisavam a língua por meio de um ou dois informantes ou examinavam ainda seu próprio conhecimento sobre a língua, descartando os fatores extralinguísticos ou sociais.

Contrário ao pensamento de Saussure, Labov (2008 [1972]) defende, portanto, a relação imbricada e evidente entre língua e sociedade. Por isso argumenta que o termo sociolinguística lhe parece até redundante, pois, segundo ele, não é possível entender a língua sem considerar a sociedade, e viceversa. Então, afirma: "Por vários anos, resisti ao termo sociolingüística, já que ele implica que pode haver uma teoria ou prática lingüística bem-sucedida que não é social" (p. 13). A fim de enfatizar que a língua é uma forma de comportamento social, Labov lembra que crianças submetidas a isolamento não utilizam a língua, porque esta é usada em um contexto social, para os seres humanos exporem suas necessidades, opiniões e emoções uns aos outros (p. 215).

Em virtude das pressões sociais as quais estão sempre atuando sobre a língua, não 
é possível compreender por que variações linguísticas ocorrem sem levar em conta a vida social da comunidade investigada. Dessa forma, de acordo com a teoria sociolinguística, a sistematização da variação e da mudança linguística precisa ser entendida através de fatores internos e sociais. De acordo com Mateus (2001, p. 8):

0 espaço de discussão sobre as relações entre língua e cultura tem sido progressivamente preenchido pelas preocupações dos sociolinguistas no que respeita às questões da variação linguística. A grande importância atribuída à variação das línguas, em interacção com a variação das sociedades, abriu campo para o estudo dos factores intervenientes nessa variação, internos e externos, históricos e resultantes do contacto entre línguas, e para o desenvolvimento das perspectivas teóricas nesta área.

Para Mattos e Silva (2008), o fundamental da proposta da teoria da variação e da mudança está na nova compreensão da estrutura linguística, uma vez que a especulação linguística dos estruturalistas e gerativistas, baseada na concepção de estrutura linguística como homogênea, é considerada incompatível com a realidade. A autora acrescenta que, para os sociolinguistas americanos, a estrutura linguística é intrinsecamente heterogênea, e essa relação entre estrutura e heterogeneidade são essenciais para o funcionamento real das línguas.

Assim, para a sociolinguística laboviana, o reconhecimento da heterogeneidade linguística parte da noção de que as línguas variam, ou seja, diferentes variantes linguísticas concorrem entre si, em determinado contexto, e têm o mesmo significado referencial. Essa variação pode resultar em mudança linguística, que pode ser detectada com base nos fundamentos empíricos desenvolvidos por Weinreich, Labov e Herzog (2006 [1968]).
Dentre as questões fundamentais dos estudos sociolinguísticos, busca-se identificar se determinado fenômeno aponta para uma variação ou se há indícios de mudança linguística. Desse modo, as variáveis sociais, tradicionalmente controladas nas pesquisas variacionistas, a fim de investigar a variação e a mudança, são o sexo/gênero, a escolaridade e a faixa etária do informante.

Entende-se que as diferenças entre sexo/ gênero interferem nos usos linguísticos, com as mulheres optando pelo uso linguístico da variante de prestígio mais que os homens. Porém, esta é uma realidade que pode ser mais comum nos centros urbanos; em comunidades rurais, como aponta Lucchesi (2009), em estudo sobre a concordância de gênero no português de Helvécia-BA, os homens podem usar mais a variante de prestígio devido ao fato de terem mais contato com o mundo exterior à comunidade.

Pressupõe-se, também, que as mulheres podem encabeçar uma mudança quando determinada variante inovadora não é estigmatizada. Contudo, é importante destacar que essa realidade varia conforme a comunidade, pois, em alguns casos, são os homens que usam mais a variante de prestígio, devido, por exemplo, ao mercado ocupacional.

No que diz respeito à escolaridade, além de a escola ser um agente na promulgação de variantes de prestígio, o status adquirido com a escolaridade motiva o falante mais escolarizado a recorrer mais ao uso dessas variantes. Quanto à faixa etária, pesquisas comprovam que os jovens tendem a implementar a variante inovadora, enquanto os mais velhos mantêm mais a variante padrão, lembrando que faixas intermediárias poderão liderar os índices do uso padrão, devido ao fato de estarem mais presentes no mercado de trabalho. Além desses fatores sociais, 
tem-se controlado a influência do status social, da profissão, da religião, entre outros.

Se diferentes variantes estiverem concorrendo entre si, coexistindo mais ou menos com a mesma frequência, diz-se que ocorre uma variação linguística; porém, a variação linguística pode resultar em mudança linguística. Esta, por sua vez, pode ser observada ainda em seu curso ou quando já estiver definida. Quando se trata de mudança linguística em progresso, verifica-se que uma das variantes se sobrepõe à(s) outra(s), isto é, uma é mais usada que outra(s) e anuncia uma possível mudança. E, quando a mudança está definida, apenas uma das variantes, geralmente a inovadora, prevalece e a(s) outra(s) entra(m) em desuso.

É importante destacar que, além de inovar os estudos da ciência linguística com os fundamentos empíricos, a sociolinguística trouxe contribuições para o desenvolvimento da educação, visto que a formação de professores nos cursos de letras passou a atentar para a heterogeneidade linguística e social, lançando reflexões sobre um ensino descritivo de língua, respaldado no respeito às diferentes variedades linguísticas e seus contextos reais de uso.

\section{Polarização sociolinguística no português brasileiro}

De acordo com Dante Lucchesi (2004) o português brasileiro é caracterizado pela polarização sociolinguística, fenômeno que é explicado por razões sócio-históricas. 0 autor considera a distinção entre norma culta $^{1}$ e popular, afirmando ser a primeira uma

1 De acordo com Faraco (2008, p. 54), é preciso trabalhar criticamente com a noção de norma culta, pois o termo pode sugerir que há outras normas "incultas". Assim, a expressão norma culta deve ser compreendida como a norma linguística usada em determinadas situações e "por grupos sociais que têm estado mais diretamente com a cultura escrita". consequência da herança da elite colonial, ou seja, refere-se aos padrões de comportamento linguístico dos brasileiros que têm formação escolar e acesso a todos os espaços da cidadania; e a norma popular define os padrões de comportamento linguístico das pessoas que são privadas dos direitos básicos e mantidas "na exclusão e na bastardia social” (LUCCHESI, 2004, p. 87).

Ainda segundo Lucchesi (op. cit.), no interior do Brasil, a língua portuguesa era adquirida em contextos precários pelos escravos, que se comunicavam também entre si, usando uma língua africana. Portanto foi dessa maneira que "a língua portuguesa se foi disseminando entre a população pobre, de origem predominantemente indígena e africana, nos três primeiros séculos da história do Brasil". Contudo, no início do século $\mathrm{XX}$, a realidade social brasileira passou por algumas mudanças, devido à industrialização e ao crescimento urbano, o que provoca a "democratização dos padrões culturais e linguísticos" (LUCCHESI, 2004, p. 79).

Lucchesi (2017) considera o processo de periodização da história da língua portuguesa no Brasil a fim de propor a superação da perspectiva unitária da história sociolinguística do Brasil, adotando-se uma concepção 'polarizada'. De acordo com o autor, há quatro fases que constituem a história do português no Brasil: na primeira, nomeada de "Tupinização da costa", que compreende o período de 1000 até 1532 , o tupi e o tupinambá eram as línguas mais faladas na costa; na segunda fase (1532-1695), do "Multilinguismo generalizado", o português convivia com as línguas gerais indígenas e línguas francas africanas; na terceira fase (1695-1930), da "Homogeneização linguística", houve a imposição do português, que reduziu o multilinguismo; por fim, na quarta fase (1930 até hoje), do "Nivelamento lin- 
guístico", a industrialização e a urbanização influenciaram a difusão da norma urbana culta e o apagamento das marcas do contato na norma popular. Além disso, na quarta fase, a norma culta se distancia do padrão europeu, contudo a desigualdade social mantém a polarização sociolinguística.

Se por um lado a polarização sociolinguística persiste no Brasil; por outro, as normas culta e popular caminham numa aproximação. Lucchesi (2004) afirma que a massificação do ensino básico e o desenvolvimento dos meios de comunicação cederam espaço para que algumas mudanças ocorressem, visto que as normas culta e popular passaram a se aproximar. Assim, ao longo do século XX, observa-se uma tendência de mudança "para cima", na qual o chamado português popular vai em direção ao português culto; e, também, acontece uma mudança "para baixo" no português culto, que se distancia da norma padrão europeia.

A respeito da variação entre FP e PI, apesar de a escola não defender o uso de FP no domínio irrealis da mesma forma incisiva que defende o uso da concordância de número e de outras variantes de prestígio, pesquisas realizadas em diferentes regiões do Brasil, conforme veremos na seção 4 , atestaram a relação entre escolarização e o uso de FP, sendo que os mais escolarizados tendem a usar menos o PI em lugar de FP.

\section{Pesquisas realizadas sobre o fenômeno em estudo: uma análise bibliográfica}

Diferentes estudos sobre a variação entre FP e PI já foram desenvolvidas em diferentes regiões do Brasil. Descreve-se, portanto, nesta seção, algumas dessas pesquisas com o objetivo de analisar, sobretudo, se os resultados apontam para um fenômeno de va- riação estável ou de mudança em progresso. Para facilitar a análise, os estudos serão apresentados de acordo com regiões do Brasil, considerando trabalhos das regiões $\mathrm{Su}$ deste, Sul e Nordeste ${ }^{2}$, que serão descritos nesta ordem porque levaremos em conta a temporalidade, ou seja, a primeira pesquisa variacionista, de que temos ciência, sobre o tema, é da região Sudeste, o que justifica a apresentação na sequência mencionada.

Da Região Sudeste, comentaremos as pesquisas de Costa (1997; 2003), realizada no Rio de Janeiro; Sousa (2007), em Juiz de Fora (MG); e a de Tesch (2007), em Vitória (ES).

A pesquisa inicial de Costa (1997) foi em sua dissertação de mestrado, na qual investiga a variação entre FP e o PI no português informal do Rio de Janeiro, por meio de amostras de língua falada (Amostra Censo do Projeto PEUL) e de língua escrita (cartas pessoais), considerando as formas simples e perifrásticas dos dois tempos como variantes. Consoante a autora, os resultados mostraram o favorecimento de FP (65\% dos dados) na modalidade escrita, mesmo em se tratando de um registro informal da língua, visto que o corpus foi constituído de cartas pessoais. Já na amostra de língua falada, com exceção da variante IRIA+V, a qual representou apenas $2 \%$ dos dados, a distribuição das variantes foi mais equilibrada: FP, 34\%; PI, $41 \%$; IA+V, $23 \%$.

Dentre outras constatações, os resultados de Costa (1997) evidenciaram que o FP é uma forma mais conservadora, porque, na língua falada, essa foi a variante preferida pelos mais velhos e por pessoas com mais tempo de escolarização. Já a forma IA+V é a forma inovadora, que predomina na fala dos mais jovens.

2 Não encontramos estudos sobre o fenômeno nas regiões Norte e Centro Oeste. 
Segundo Costa (2003, p. 9), essa pesquisa sincrônica, realizada em 1997, ocasionou “algumas constatações interessantes que despertaram a curiosidade para um estudo diacrônico do fenômeno". Tendo constatado, na primeira pesquisa, que a variante $I A+V$ era mais usada pelos mais jovens e que havia uma variação equilibrada entre o FP e o PI na amostra de língua falada, Costa (2003) decidiu analisar, em sua tese de doutorado, se havia, no português brasileiro, uma tendência a se utilizarem as formas simples em detrimento das perifrásticas e se a variação entre FP e PI "vem permanecendo estável no decorrer das últimas décadas ou se se estabilizou nas últimas décadas" (p. 10). Assim, investigou a mudança linguística em tempo real de longa e de curta duração.

Amostras de fala do projeto PEUL foram usadas para o estudo em tempo real de curta duração, através de dois métodos de estudo da variação e mudança: tendência e painel. Quanto ao estudo do fenômeno em tempo real de longa duração, Costa (2003) utilizou dados de peças teatrais, abrangendo o início do século XVIII até o final do século XX. Esses estudos fizeram a pesquisadora perceber que havia diferentes disputas em mais de um plano: "de um lado as perífrases com 'ir' e 'haver de', de outro, as formas flexionadas de IMP ${ }^{3}$ e FP. E, no conjunto, a luta entre formas simples e perifrásticas" (p. 133).

$\mathrm{Na}$ pesquisa em tempo real de longa duração, a pesquisadora observou a presença da perífrase 'havia de + infinitivo' em contexto irrealis. A análise quantitativa apontou que o uso de 'havia de + infinitivo' desaparece nos textos das peças teatrais a partir da segunda metade do século XX e, nesse mesmo período, a perífrase $I A+V$ começa a se destacar e tem seu percentual dobrado a

3 Sigla usada pela pesquisadora para se referir ao pretérito imperfeito. cada vinte anos, a partir da década de quarenta. Com o aumento na frequência, $\mathrm{IA}+\mathrm{V}$ torna-se a variante mais usada nos textos teatrais das últimas duas décadas do século $\mathrm{XX}$, sendo favorecida pela classe mais jovem, o que corrobora a hipótese da autora de que $\mathrm{IA}+\mathrm{V}$ seria uma forma inovadora.

A pesquisa do tipo painel mostrou a relação entre o uso de FP e a escolaridade dos informantes. A análise dos dados da Amostra Censo revelou que os falantes, recontactados cerca de vinte anos depois, "que ingressaram no nível superior, neste intervalo, mudaram seu comportamento linguístico no sentido de sistematicamente apresentarem um acréscimo no uso da variante FP" (p. 134). Já o estudo de tendência apontou que "há uma distribuição complementar entre IMP e FP através dos níveis de instrução", ou seja, "quanto mais anos de escolaridade possui o informante, maior o uso de FP e, quanto menos tempo na escola, maior o uso de IMP" (p. 135).

O estudo de Sousa (2007) analisou a variação entre o futuro do pretérito e o pretérito imperfeito na expressão da hipótese. Debruçando-se sobre textos da língua escrita, as amostras usadas pela autora foram compostas de redações produzidas no ano de 2006, por alunos da sexta série do ensino fundamental e do segundo ano do ensino médio de dois colégios, um da rede particular de Juiz de Fora e outro vinculado à Universidade Federal de Juiz de Fora. Além disso, para realizar o contraponto, Sousa usa trechos de correspondências trocadas entre a Coroa Portuguesa e autoridades da Coroa no Brasil e/ou pessoas influentes nas vilas, durante o século XVIII.

De acordo com Sousa (2007), os dados encontrados nas redações apresentaram informações diferentes ao que se esperava, por isso "as propostas dirigidas ao ensino 
médio foram aplicadas, num segundo momento, também a alunos do curso de Letras da Universidade Federal de Juiz de Fora" (p. 13).

A pesquisadora encontrou nos corpora analisados 33 ocorrências do uso do pretérito imperfeito com ideia de continuidade; 70 ocorrências de futuro do pretérito para indicar hipótese; e 12 ocorrências de pretérito imperfeito também para expressar hipótese. Conforme Sousa (2007), mesmo que a maioria das ocorrências que expressaram hipótese tenham sido de futuro do pretérito, há indícios de competição entre o futuro do pretérito e o pretérito imperfeito.

Dessa forma, Sousa (2007) questiona em sua pesquisa se haveria uma tendência de o pretérito imperfeito suplantar o futuro do pretérito na expressão da hipótese ou se ocorre uma mudança linguística em curso. Na opinião da pesquisadora, enquanto a escola e outros veículos que promovem a normatização da língua continuarem a "transmitir a ideia de status elevado de língua padrão associada ao uso do futuro do pretérito, a oscilação entre este e o imperfeito (remetendo-se à hipótese) estará ligada à modalização entre formal versus informal".

Por outro lado, Sousa (2007) argumenta que o fato de ter encontrado, em diferentes períodos, a alternância entre o pretérito imperfeito e o futuro do pretérito em textos escritos pressupõe uma indicação de tendência à mudança, com a primazia do uso do pretérito imperfeito. Porém, segundo a autora, para isso acontecer, o futuro do pretérito teria de deixar de ser difundido pelos meios reguladores da língua-padrão.

A pesquisa de Tesch (2007) investiga, a partir dos fundamentos da sociolinguística variacionista, os contextos linguísticos e sociais ligados à variação entre FP e PI, além de se basear nos pressupostos do funciona- lismo linguístico. Usando amostras de fala de 46 entrevistas, coletadas entre 2001 e 2002 com informantes de Vitória (ES), Tesch encontrou 1080 ocorrências de variantes com a noção de irrealis, nas formas sintéticas e perifrásticas do futuro do pretérito e do pretérito imperfeito.

Os resultados de todos os dados juntos, ou seja, amalgamadas as formas simples e perifrásticas, mostraram preferência pelo uso do pretérito imperfeito (58\%) em detrimento do futuro do pretérito (42\%). Contudo, ao analisar separadamente as formas simples e perifrásticas, o FP foi a variante predominante. Nesse caso, as ocorrências de FP representaram 41\% dos dados; as de PI, 38\%; as de IA + V, 21\%; e as de IRIA + V não totalizou nem $1 \%$ dos dados.

Conforme a análise de Tesch (2007), a faixa etária influencia no uso das formas variantes PI e IA + V. A autora argumenta que o PI pode ser substituído pela forma perifrástica, "uma vez que a tendência maior ao uso de IA + V está nos mais jovens (.64) e as inovações linguísticas são trazidas por essa faixa etária" (p. 106). Já os mais velhos desfavorecem o uso da perífrase e preferem usar o PI na forma sintética. Tesch ressalta, também, que a variante PI, não pode ser classificada como uma forma conservadora ou inovadora, nem como prestigiada ou estigmatizada, pois "é possível encontrar em algumas gramáticas normativas o seu emprego como alternativa coloquial ao futuro do pretérito" (p. 109).

Outro fator considerado significativo na escolha das variantes, segundo Tesch, foi a 'Escolarização'. Os participantes da pesquisa com ensino superior e médio preferiram o uso de FP, enquanto as pessoas com ensino fundamental favorecem o uso da variante PI, resultados que "confirmam a hipótese de que a escola possibilita uma maior aproxi- 
mação do falante em relação às formas recomendadas pela norma” (p. 113-114).

Na região Sul do país, temos a pesquisa de Karam (2000), que analisou a variação entre o futuro do pretérito, o pretérito imperfeito e a perífrase verbal IR+infinitivo na fala do Rio Grande do Sul, considerando quatro cidades do estado: Flores da Cunha, Panambi, São Borja e Porto Alegre. Usando amostras de fala do projeto VARSUL (Variação Linguística Urbana na Região Sul do Brasil), a proposta da autora buscou avaliar se a variação entre o FP e PI seria uma variação estável e se a perífrase indicaria uma mudança em curso, atentando-se às variáveis linguísticas e sociais que poderiam influenciar o fenômeno linguístico.

No procedimento quantitativo dos dados, Karam optou por desenvolver rodadas diferentes, sendo uma binária, considerando somente as formas sintéticas de FP e PI, e outra ternária, que acrescentou a perífrase verbal. A rodada terciária demonstrou mais relevância para as respostas que a autora se propôs a encontrar, pois as variáveis sociais foram apontadas como significativas apenas na rodada ternária.

Assim, os resultados evidenciaram que a perífrase IR+infinitivo é mais comum na fala das mulheres e dos participantes mais jovens, corroborando a hipótese da autora de que o uso dos verbos perifrásticos são possivelmente indícios de mudança em curso.

No que diz respeito às pesquisas realizadas no Nordeste, apresentaremos os estudos de Freitag e Araújo (2011), em Itabaiana (SE); a de Santos (2014), em Feira de Santana (BA); e a de Brito (2018), em Natal (RN).

0 estudo de Freitag e Araújo investigou o uso das formas do passado condicional no português falado em Itabaiana/SE, considerando as formas sintéticas e perifrásticas do futuro do pretérito e do pretérito imperfei- to. Para a realização da pesquisa, as autoras adotaram os princípios da sociolinguística variacionista e do funcionalismo.

0 corpus foi constituído por 20 entrevistas, com informantes de nível superior, e as autoras encontraram 93 ocorrências do fenômeno, sendo 65 de FP, 10 de PI, 11 de IA+V e 7 de IRIA+V. Em virtude da baixa recorrência do fenômeno na amostra considerada, Freitag e Araújo (2001) optaram por amalgamar as formas perifrásticas e, assim, obtiveram resultados estatisticamente mais relevantes.

As pesquisadoras analisaram variáveis linguísticas e, dentre os resultados mais significativos, o trabalho aponta que o 'tipo semântico-cognitivo do verbo' é uma das variáveis que contribui para a variação do fenômeno, sendo que quatro fatores foram testados: estado, atividade, modalidade e cognição. Os resultados mostraram que o FP foi mais frequente em todos os tipos de verbos.

Freitag e Araújo (2001) testaram também a variável 'tipo de sequência discursiva', a qual é constituída das sequências narrativa, opinativa e explicativa. As autoras partiram do princípio de que os textos opinativos e explicativos favoreceriam o uso de FP e das formas perifrásticas, hipóteses que foram comprovadas: o uso de FP e das formas perifrásticas foram mais recorrentes em sequências opinativas e em contextos explicativos; enquanto o PI foi mais usado nas sequências narrativas.

0 fato de o uso variante FP se destacar na amostra de Itabaiana nos chama a atenção e esse resultado corrobora o pressuposto de que as pessoas com ensino superior tendem a favorecer essa variante. Lembramos que as entrevistas analisadas na pesquisa de Freitag e Araújo foram somente de informantes com ensino superior. 
Santos (2014) investigou a variação entre FP e PI no português falado em Feira de Santana-BA por meio de entrevistas do projeto A Língua Portuguesa no Semiárido Baiano, considerando três níveis de escolaridade: ensino fundamental incompleto, ensino médio e ensino superior. Os resultados apontaram que, naquela comunidade, a variação entre o FP (48\% dos dados) e o PI ( $52 \%$ dos dados) é equilibrada e estável.

Dentre os resultados mais significativos, concluiu-se que os falantes favorecem o uso de PI em texto narrativo, enquanto que, ao expor sua opinião em sequências argumentativas ou se expressar através de listas de atitudes hipotéticas, promovem o uso de FP. Outra variável linguística relevante foi a estrutura verbal: as formas sintéticas tendem a promover o uso de FP; e as perifrásticas, o uso do PI.

No que diz respeito às variáveis sociais, a pesquisa de Santos (2014) revelou que os falantes menos escolarizados promovem o uso de PI; enquanto a variante FP é mais usada pelos mais escolarizados. Como o fenômeno da variação entre FP e PI já é reconhecido em gramáticas, Santos defendeu na sua pesquisa a hipótese de variação estilística, pois os ambientes mais formais frequentados pelas pessoas mais escolarizadas, o meio social e o status do falante podem interferir, o que explicaria a preferência pelo emprego de FP na fala dos informantes com nível superior.

A tese de Brito (2018) analisa a alternância entre as formas verbais simples e perifrásticas do futuro do pretérito e do pretérito imperfeito em orações condicionais, ou seja, especificamente em construções "se p, então q". Baseando-se no aparato teórico-metodológico da Sociolinguística variacionista e do Funcionalismo linguístico norte-americano, a amostra analisada foi composta por 346 construções condicionais retiradas de comentários na rede social Facebook.

Para a análise das variáveis linguísticas ou semântico-pragmáticas, Brito se amparou da explicação funcionalista, baseada em Givón (1995), para aventar a hipótese de que fatores mais marcados poderiam influenciar no uso de PI. Segundo Brito (2018: 35):

0 princípio da marcação linguística é considerado, no âmbito dos estudos funcionalistas, um dos mais relevantes para a organização da língua. Ele prevê que as categorias que são cognitivamente marcadas (isto é, complexas) tendem a ser codificadas através de formas - ditas formas marcadas -, que se caracterizam por maior complexidade estrutural (elaboração, extensão), maior complexidade cognitiva (em termos de memória, esforço de atenção e tempo de processamento) e menor frequência em relação as suas contrapartes não marcadas.

Dessa forma, consoante a pesquisadora, a conversação cotidiana, que se destaca pela informalidade, caracteriza-se por ser um contexto menos marcado, e as formas menos marcadas comuns nesse cenário são, por sua vez, "frequentes e mais salientes cognitivamente, isto é, menos complexas quanto ao processamento" (p. 36). Em contrapartida, "as formas marcadas na conversação cotidiana são as formas marcadas em geral, sendo mais frequentes em situações de interação mais marcadas, cujo ápice é o discurso acadêmico escrito" (p.36).

Os resultados de Brito (2018) corroboraram sua hipótese, visto que a frequência de FP foi mais recorrente em contextos mais marcados. Um exemplo de variável que confirmou esse pensamento foi Tópico/assunto: ao passo que o fator "Assunto complexo ou embaraçoso" favoreceu o FP, o fator "Assunto pessoal" favoreceu o PI. Assim, a pesqui- 
sadora concluiu que os fatores "mais marcados favorecem FP, a forma mais marcada no contexto dos comentários no Facebook, enquanto fatores definidos como menos marcados favorecem PI, a forma menos marcada no contexto em questão" (p. 121).

Ainda de acordo com Brito, os fatores sociais idade e sexo revelaram a possibilidade de mudança em progresso, cuja liderança é assumida pelas mulheres na direção do uso mais frequente de PI em comentários no Facebook. Já em relação à escolaridade, os resultados evidenciaram que o FP foi mais usado entre os participantes com ensino superior, enquanto o PI foi favorecido entre aqueles com ensino fundamental e médio.

\section{Conclusão}

Partindo da indagação a respeito da possibilidade de variação estável ou de mudança em curso, envolvendo a alternância entre o futuro do pretérito e o pretérito imperfeito no português brasileiro, a revisão bibliográfica aqui apresentada nos permitiu chegar a algumas conclusões.

Ao observar o cenário das variáveis sociais consideradas nas pesquisas, compreendemos que a variável escolaridade aponta para uma direção oposta ao caminho da mudança, ou seja, independente da região do país, vimos que quanto mais escolarizado for o falante, mais usará o FP, como revelaram as pesquisas de Costa (2003), Tesch (2007), Sousa (2007), Santos (2014) e Brito (2018). Dessa forma, a escolarização ou possivelmente o status de escolarização, conforme a proposta apresentada por Santos (2014), tende a inibir o uso de PI e das formas perifrásticas.

A relação entre a escolarização e o uso de FP nos remete ao argumento de Câmara Jr. (1975) de que as formas de futuro são de uso parcial desde o latim, uma vez que são empregadas em contextos mais específicos, como na língua escrita e em determinadas situações mais formais. Os espaços que promovem o uso de FP seriam, portanto, mais comuns entre os falantes com maior nível de escolaridade.

Por outro lado, vimos que os resultados de diferentes pesquisas apontaram que o fenômeno variável em estudo caminha em direção à mudança, isto é, estaria passando por mudança em curso, pois o uso da perífrase com o verbo ir é a forma inovadora, a qual se apresenta na fala dos jovens e das mulheres. Assim, a partir desses estudos, tivemos indícios para responder ao nosso questionamento inicial; porém, somente com o desenvolvimento de outras pesquisas é que poderemos ter um panorama mais completo e compreender com mais precisão as características sociolinguísticas desse fenômeno no português brasileiro.

\section{Referências}

BRITO, Nara Jaqueline Avelar. Alternância entre o futuro do pretérito e pretérito imperfeito do indicativo no domínio funcional da condição contrafactual em comentários do facebook. Tese (doutorado) - Universidade Federal do Rio Grande do Norte, Centro de ciências humanas, letras e artes, Programa de pós-graduação em estudos da linguagem. Natal, 2018.

CÂMARA JR., Joaquim Mattoso. História e estrutura da língua portuguesa. Rio de Janeiro: Padrão, 1975.

CÂMARA, Tânia Maria Nunes de Lima. Alternância do uso do pretérito imperfeito e do futuro do pretérito no discurso oral. Augustus, Rio de Janeiro, v. 7, nº 15, jul./dez., 2002.

COSTA, Ana Lúcia dos Prazeres. A variação entre formas de futuro do pretérito e de pretérito imperfeito no português informal no Rio de Janeiro. Dissertação (Mestrado em Linguística) - Faculdade de Letras - Universidade do Rio de Janeiro, Rio de Janeiro, 1997.

COSTA, Ana Lúcia dos Prazeres. o futuro do 
pretérito e suas variantes no português do Rio de Janeiro: um estudo diacrônico. 132 p. Tese (Doutorado em Linguística) - Faculdade de Letras - Universidade do Rio de Janeiro, Rio de Janeiro, 2003.

FARACO, Carlos Alberto. Norma culta brasileira: desatando alguns nós. São Paulo: Parábola Editorial, 2008.

FREITAG, Raquel Meister Ko; ARAÚJO, Andréia Silva. Passado condicional no português: formas e contextos de uso. Caligrama - Revista de Estudos Românicos da Faculdade de Letras da UFMG, 2011.

GIVÓN, Talmy. Funtionalism and grammar. Amsterdam /Philadelphia: J. Benjamins, 1995.

GIVÓN, Talmy. Syntax: an introduction. Amsterdam/Philadelphia: John Benjamins, 2001.

KARAM, L. A variação entre o futuro do pretérito, o imperfeito e a perífrase com o verbo ir na fala do RS. Dissertação (Mestrado em Linguística) - Programa de Pós-graduação em Letras, Universidade Federal do Rio Grande do Sul, Porto Alegre, 2000.

LABOV, William. Padrões sociolinguísticos. Trad.: Marcos Bagno; Marta Scherre e Caroline Cardoso. São Paulo: Parábola, 2008 [1972].

LUCCHESI, Dante. Sistema, mudança e linguagem: um percurso da lingüística moderna. São Paulo: Parábola, 2004.

LUCCHESI, Dante. A realização do sujeito pronominal. In: LUCCHESI, Dante; BAXTER, Alan e RIBEIRO, Ilza (org.). O português afro-brasileiro. Salvador: EDUFBA, 2009.

LUCCHESI, Dante. A periodização da história sociolinguística do Brasil. Delta [online]. 2017, vol.33, n.2, pp.347-382. Disponível em: https:// www.scielo.br/pdf/delta/v33n2/1678-460Xdelta-33-02-00347.pdf. Acesso em: 10. Jul. 2020.

MATEUS, Maria Helena Mira. Se a língua é um fator de identificação cultural, como compreender que uma língua viva em diferentes culturas? Disponível em: http://periodicos.ufc. br/revletras/article/view/2246/1716. Acesso em: 20 jul. 2020.

MATTOS, Priscila Brügger. A evolução dos tempos verbais. In: SILVA, José Pereira. História da língua portuguesa. Cadernos da Pós-Graduação em Língua Portuguesa. Rio de Janeiro, UERJ, no 1, 2001, p. 24-31.

MATTOS E SILVA, Rosa Virgínia. Caminhos da linguística histórica - ouvir o inaudível. São Paulo: Parábola Editorial, 2008.

MECER, José Luiz da Veiga. 0 futuro nas línguas românicas. Revista da Abralin, v. Eletrônica, n. Especial, p. 385-394, 1를 2011.

SANTOS, Aline da Silva. A variação entre o futuro do pretérito e o pretérito imperfeito no português falado em Feira de Santana-BA. 132 f. Dissertação (Mestrado em Estudos Linguísticos) - Universidade Estadual de Feira de Santana, Feira de Santana, 2014.

SAUSSURE, Ferdinand. Curso de linguística geral. 34aㅡ ed. Trad. Antônio Chelini, José Paulo Paes e Izidoro Blikstein. São Paulo: Cultrix, 2012 [1916].

SOUSA, Fernanda Cunha. A alternância entre o pretérito imperfeito e futuro do pretérito na expressão da hipótese. $130 \mathrm{f}$. Dissertação (Mestrado em Linguística) - Faculdade de Letras - Universidade Federal de Juiz de Fora. Juiz de Fora, 2007.

TESCH, Leila Maria. A variação no âmbito do irrealis entre as formas do futuro do pretérito e pretérito imperfeito do indicativo na fala capixaba. 152 f. Dissertação (Mestrado em Linguística). Programa de Pós-Graduação em Linguística da Faculdade de Letras da Universidade Federal do Rio de Janeiro, Rio de Janeiro, 2007.

WEINREICH, Uriel; LABOV, William; HERZOG, Marvin. Fundamentos empíricos para uma teoria da mudança linguística. Trad. Marcos Bagno; rev. téc. Carlos Alberto Faraco. São Paulo: Parábola. 2006 [1968].

Recebido em: 15/04/2021 Aprovado em: 02/08/2021 